\title{
Efficacy and safety of gastric exposed endoscopic full-thickness resection without laparoscopic assistance: a systematic review
}

(이요 $\odot$

\begin{abstract}
Authors
Institutions

1 Digestive Endoscopy Service, Department of Diagnostic and Therapeutic Services, IRCCS - ISMETT Palermo, Italy

2 Information Technology, IRCCS - ISMETT Palermo, Italy
\end{abstract}

Antonino Granata ${ }^{1}$, Alberto Martino ${ }^{1}$, Michele Amata ${ }^{1}$, Dario Ligresti ${ }^{1}$, Fabio Tuzzolino², Mario Traina ${ }^{1}$ submitted 5.2.2020

accepted after revision $\quad 25.5 .2020$

Bibliography

Endosc Int Open 2020; 08: E1173-E1182

DOI 10.1055/a-1198-4357

ISSN 2364-3722

(c) 2020. The Author(s).

This is an open access article published by Thieme under the terms of the Creative Commons Attribution-NonDerivative-NonCommercial License, permitting copying and reproduction so long as the original work is given appropriate credit. Contents may not be used for commercial purposes, or adapted, remixed, transformed or built upon. (https://creativecommons.org/licenses/by-nc-nd/4.0/)

Georg Thieme Verlag KG, Rüdigerstraße 14,

70469 Stuttgart, Germany

Corresponding author

Martino Alberto, MD, Endoscopy Service, IRCCS - ISMETT, Via Tricomi, 5, 90127 Palermo, Italy

Fax: +39-091-2192400

alberto-martino@libero.it

\section{ABSTRACT}

Background and study aims Exposed endoscopic fullthickness resection (Eo-EFTR) without laparoscopic assistance is a minimally invasive natural orifice transluminal endoscopic surgery (NOTES) technique that has shown promising efficacy and safety in resection of gastric submucosal tumors (G-SMTs) arising from muscularis propria (MP). However, data on the efficacy and safety of gastric EoEFTR mostly come from relatively small retrospective studies and concern regarding its use still exists. The aim of our systematic review was to assess the efficacy and safety of gastric Eo-EFTR without laparoscopic assistance.

Methods A detailed MEDLINE and EMBASE search was performed for papers published from January 1998 to November 2019 and reporting on gastric Eo-EFTR without laparoscopic assistance. The search strategy used the terms "endoscopic full thickness resection" and "gastric" or "stomach". The primary outcomes were complete resection and surgical conversion rates. The secondary outcomes were overall major adverse events, delayed bleeding, delayed perforation, peritonitis, abdominal abscess and/or abdominal infection and successful Eo-EFTR.

Results Fifteen Asian studies were included in our final review, providing data on 750 Eo-EFTR-treated G-SMTs. The per-lesion rate of complete resection and surgical conversion were $98.8 \% \mid 0.8 \%$, respectively. The per-lesion rate of major adverse events, delayed bleeding, delayed perforation and peritonitis, abdominal abscess and/or abdominal infection was $1.6 \%|0.5 \%| 0.1 \% \mid 0.9 \%$, respectively. The perlesion rate of successful Eo-EFTR (i.e. complete tumor resection and effective endoscopic defect closure) was $98.3 \%$.

Conclusions Eo-EFTR without laparoscopic assistance appears to be highly effective and safe NOTES for removing deep G-SMTs, particularly those arising from MP layer.

\section{Introduction}

According to the latest National Comprehensive Cancer Network (NCCN) guidelines either suspected or histologically defined gastric gastrointestinal stromal tumors (GISTs) larger than $20 \mathrm{~mm}$ in diameter should be removed with histologically negative margines [1]. Furthermore, patients with suspected or defined GISTs less then $20 \mathrm{~mm}$ in diameter which display highrisk endoscopic ultrasound (EUS) features (i.e. irregular bor- ders, cystic spaces, ulcerations, echogenic foci and heterogeneity) should undergo complete surgical resection. Given the limited intramural extension of GISTs, laparoscopic segmental or wedge resection is currently regarded as the gold standard for their treatment [1]. However, in recent years, a novel minimally invasive technique called exposed endoscopic full-thickness resection (Eo-EFTR) without laparoscopic assistance has emerged as a promising approach with good efficacy and safety in the resection of gastric submucosal tumors (G-SMTs) origi- 
nating from the muscularis propria (MP) through natural orifice transluminal endoscopic surgery (NOTES) [2-6].

Endoscopic full-thickness resection was first described in 1998 by Suzuki et al [7]. In 2001, the same group reported the effectiveness of endoscopic full-thickness resection (EFTR) with the use of a ligation device for the treatment of two rectal and one duodenal neuroendocrine tumors in humans [8]. A few years later, Ikeda et al. reported EFTR using the ESD technique on a porcine stomach [9] and Zhou et al. translated this technique into clinical practice (26 cases of gastric SMTs) [10].

The mainstay of Eo-EFTR is a safe wall defect closure after excision to prevent peritonitis and further surgical interventions. Currently, this is mainly achieved by use of standard through-the-scope clips [10] or clips combined with endoloops $[11,12]$, whereas defect closure by use of over-the-scope clips or endoscopic suturing devices has been reported in only a few cases [13-19].

The Eo-EFTR procedure is described as follows [10]: (A) submucosal injection followed by precutting the mucosal and submucosal layer around the lesion by standard ESD technique; (B) full-thickness resection of the lesion, including the serosal layer, and (C) creation of "active perforation" after sucking away intraluminal fluid; (D) gastric wall defect closure by the use of clips or other suturing techniques.

pplication of Eo-EFTR to MP-originating G-SMTs has been partially limited by the technical difficulty involved and safety concerns, especially regarding effective defect closure achievement. Despite these limitations, an increasing number of series have recently reported on application of Eo-EFTR to gastric SMTs. However, the majority of them were retrospective and single-center studies, including only a relatively small number of cases [2-6]. When considering the relatively low frequency of major adverse events (AEs) or surgical conversions due to either AEs or technical unfeasibility, such small sample sizes prevent reliable estimates of the efficacy and safety of gastric EoEFTR. The aim of this systematic review was to assess the efficacy and safety of gastric Eo-EFTR without laparoscopic assistance.

\section{Material and methods}

Analysis and generation of inclusion criteria were performed according to the Preferred Reporting Items for Systematic reviews and Meta-Analysis (PRISMA) recommendation [20].

\section{Eligibility criteria}

All original articles published from January 1998 (the year EoEFTR was first described) to November 2019 in which Eo-EFTR without laparoscopic assistance was performed for lesions of the stomach were reviewed. Exclusion criteria included publications that exist only as an abstract, case reports, case series (<10 cases), non-human studies, review articles, position papers, editorials, commentaries, and book chapters. In case of studies from same institute and suspicion of cohort overlapping, only the study which included the highest number of patients over the longest time interval was considered for inclu- sion, while other were excluded in order to avoid data duplication.

\section{Information sources}

One investigator (AM) performed a detailed literature search of the PubMed (MEDLINE) and EMBASE electronic databases for the period 1998-2019. The search strategy was limited to articles on human subjects and written in English. The adopted search queries were as follows: "endoscopic full thickness resection" AND ("stomach" OR "gastric") AND (("1998/01/ 01"[PDat]: “2019/11/30" [PDat]) AND humans[Mesh] AND english[lang]) for MEDLINE; ('endoscopic full thickness resection'/exp OR 'endoscopic full thickness resection') AND ('stomach'/exp OR 'stomach' OR 'gastric') AND [english]/lim AND [humans]/lim AND [embase]/lim AND 1-1-1998/sd NOT $1-12-2019 / s d$ for EMBASE. The reference lists of review articles and pertinent identified studies were carefully hand-searched by one author (AM) to identify any additional relevant studies that may have been missed by the use of the abovementioned search strategy.

\section{Study selection}

Records identified by our search strategy were screened by two independent researchers (AM, AG) according to the title and abstract. Eligibility criteria were assessed by the reviewers. The full text was retrieved and reviewed for all records that showed even a remote potential for inclusion in final analysis.

\section{Data collection process and list of items}

Data extraction was performed by two independent researchers (AM, AG) by the use of predefined data extraction forms. A third author (MT) arbitrated in the event of any lack of agreement. From each record, researchers independently extracted the following information: first author, year of publication, country where the study was performed, type of study (singleor multicenter), study design, number of patients, indication for Eo-EFTR, number of Eo-EFTR-treated lesions, tumor gastric site (cardia/fundus/body/antrum), mean tumor size $(\mathrm{cm})$, depth of invasion of the tumor evaluated by preoperative EUS, type of wall defect closure technique, histopathological diagnosis (GIST/leiomyoma/schwannoma/others), mean follow-up period (months), the primary and secondary endpoints.

\section{Summary measures}

Primary endpoints of this study were as follows:

1. per-lesion rate of Eo-EFTR complete resection (i. e. en bloc resection with negative vertical and lateral resection margins at histology: $\mathrm{R} 0$ resection);

2. per-lesion rate of surgical conversion (i.e. due to either Eo-EFTR failure or adverse events). 
- Table 1 Excluded studies and reasons for exclusion.

\begin{tabular}{|c|c|c|c|}
\hline First author & Journal & Date & Exclusion \\
\hline Li & Surg Endosc & 2019 & No main outcome data \\
\hline Li & Surg Endosc & 2019 & No data distinction between EFTR and ESE \\
\hline Inayat & Clin Endosc & 2019 & $<10$ cases \\
\hline Guo & Gastroenterol Res Pract & 2019 & Data duplication; no data distinction between EFTR and ESD, STER, LECS \\
\hline Zhang & Endosc Int Open & 2019 & No main outcome data; no data distinction between EFTR and ESD \\
\hline Huang & Rev Assoc Med Bras (1992) & 2018 & Duplication \\
\hline Zhang & World J Gastroenterol & 2018 & No main outcome data \\
\hline Shi & Laparoendosc Adv Surg Tech A & 2018 & No main outcome data \\
\hline $\mathrm{Li}$ & Endoscopy & 2018 & Neo-EFTR \\
\hline Duan & Rev Esp Enferm Dig & 2018 & No main outcome data \\
\hline Andalib & Surg Endosc & 2018 & $<10$ cases \\
\hline Zhang & Surg Endosc & 2018 & EMSLD \\
\hline Yu & Surg Endosc & 2017 & No main outcome data \\
\hline Tan & Surg Endosc & 2017 & No main outcome data \\
\hline Gluzman & Transl Gastroenterol Hepatol & 2017 & $<10$ cases \\
\hline $\mathrm{Hu}$ & Medicine (Baltimore) & 2017 & Data duplication \\
\hline Zhang & Saudi J Gastroenterol & 2017 & No main outcome data; no data distinction between EFTR and ESD \\
\hline Kratt & Gastrointest Endosc & 2016 & Case report; Neo-EFTR \\
\hline Cai & Surg Endosc & 2016 & No main outcome data \\
\hline Tang & Surg Endosc & 2016 & No main outcome data \\
\hline Modayil & Gastrointest Endosc Clin N Am & 2016 & No data distinction between EFTR and STER \\
\hline Guo & Surg Endosc & 2015 & Data duplication \\
\hline Schmidt & Endoscopy & 2015 & Editorial \\
\hline Fähndrich & Endoscopy & 2015 & Neo-EFTR \\
\hline Huang & World J Gastroenterol & 2014 & Data duplication \\
\hline Stavropoulos & Gastrointest Endosc & 2014 & Case report \\
\hline Huang & World J Gastroenterol & 2014 & Data duplication \\
\hline Zhang & Surg Endosc & 2014 & No data distinction between EFTR and ESD \\
\hline Mori & Gastrointest Endosc & 2014 & Case report \\
\hline Zhang & Chin Med J (Engl) & 2013 & Data duplication \\
\hline Qin & Endoscopy & 2013 & Comment \\
\hline Huang & World J Gastroenterol & 2012 & No main outcome data \\
\hline Kopelman & Gastrointest Endosc & 2012 & Review \\
\hline Cho & Endoscopy & 2011 & Laparoscopic assistance \\
\hline Kantsevoy & Gastrointest Endosc & 2006 & Editorial \\
\hline
\end{tabular}




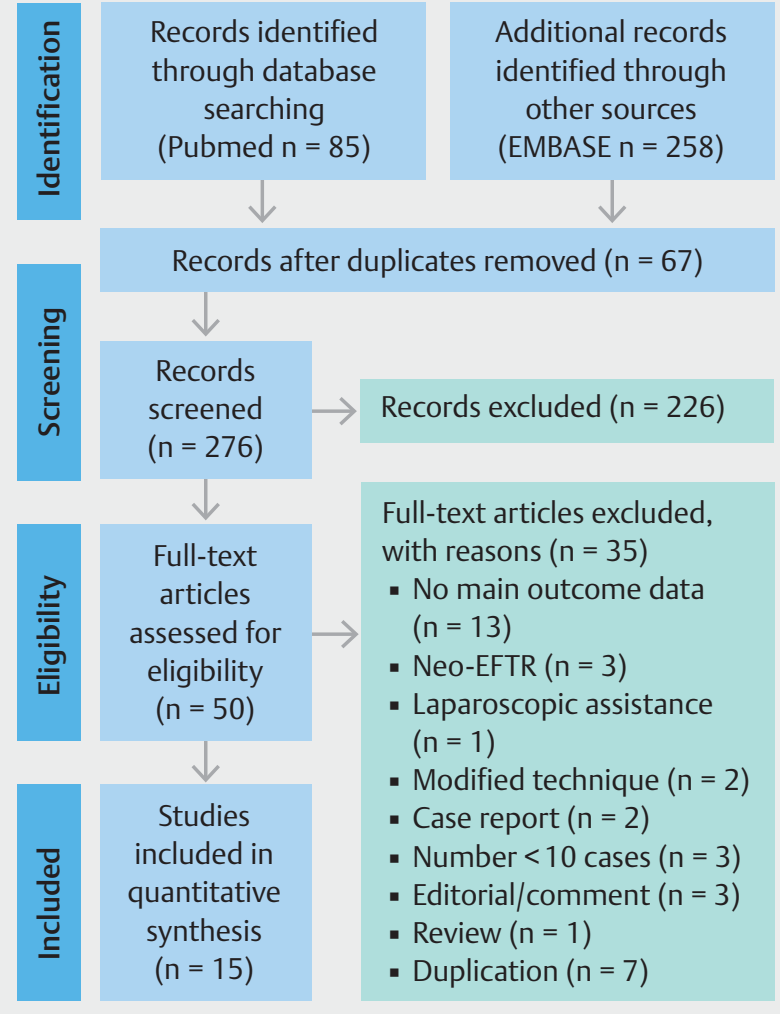

- Fig. 1 Flow chart of the study selection procedure.
Secondary endpoints included:

1. per-lesion rate of overall Eo-EFTR-related major adverse events (i.e. delayed bleeding, delayed perforation, peritonitis, abdominal abscess and/or abdominal infection);

2. per-lesion rate of delayed bleeding;

3. per-lesion rate of delayed perforation;

4. per-lesion rate of peritonitis, abdominal abscess and/or abdominal infection;

5. per-lesion rate of successful Eo-EFTR (i. e. complete resection of the tumor and effective endoscopic defect closure with neither delayed perforation occurrence nor surgical conversion need).

In case of incomplete data presentation and/or apparent conflict or inconsistency in the article attempts were made to contact authors. However, additional data were required only when involving the primary endpoints.

Descriptive statistics were used to report findings. Integrated data was provided as a mean value of the data in each study.

\section{Quality of studies}

Quality of included studies was assessed by using the Newcastle-Ottawa scale for cohort studies [21]. For each study were assessed: representativeness of the exposed cohort, ascertainment of exposure, demonstration outcome of interest not present at start, assessment of outcome, adequate length of followup. Selection of the non-exposed cohort was not considered because in all the included studies, cohort not exposed to endoscopic resection was not present. In studies comparing Eo-EFTR and other resection techniques comparability of cohorts was not considered, because not pertinent to the present review.

- Table 2 Characteristics of the included studies.

\begin{tabular}{|c|c|c|c|c|}
\hline Reference & Study design & Country & Study type & Enrollment period \\
\hline Zhou et al. [10] & Retrospective & Asian & Monocentric & 2007-2009 \\
\hline Shi et al. [11] & Retrospective & Asian & Monocentric & 2011-2012 \\
\hline Ye et al. [12] & Retrospective & Asian & Monocentric & 2009-2012 \\
\hline Feng et al. [22] & Retrospective & Asian & Monocentric & 2009-2012 \\
\hline Dong et al. [23] & Retrospective & Asian & Monocentric & 2011-2012 \\
\hline Wu et al. [24] & Retrospective & Asian & Monocentric & 2009-2014 \\
\hline Yang et al. [25] & Retrospective & Asian & Monocentric & 2012-2014 \\
\hline Lu et al. [26] & Retrospective & Asian & Monocentric & 2013-2015 \\
\hline Shi et al. [27] & Retrospective & Asian & Multicentric & 2014-2015 \\
\hline Hu et al. [28] & Prospective & Asian & Monocentric & 2015-2016 \\
\hline Sun et al. [29] & Retrospective & Asian & Monocentric & 2009-2016 \\
\hline Abe et al. [30] & Retrospective & Asian & Monocentric & 2007-2017 \\
\hline Wu et al. [31] & Retrospective & Asian & Monocentric & 2016-2017 \\
\hline Zhang et al. [32] & Retrospective & Asian & Monocentric & 2013-2017 \\
\hline Li et al. [33] & Retrospective & Asian & Monocentric & 2014-2016 \\
\hline
\end{tabular}


- Table 3 Demographics of the included studies.

\begin{tabular}{|l|l|l|l|}
\hline Reference & $\begin{array}{l}\text { Patients, } \\
\mathbf{n}\end{array}$ & $\begin{array}{l}\text { Mean age (range), } \\
\text { years }\end{array}$ & $\begin{array}{l}\text { Sex } \\
\text { male, \% }\end{array}$ \\
\hline Zhou et al. [10] & 26 & $66.5 \pm 6.9(30-76)$ & 58 \\
\hline Shi et al. [11] & 20 & $47 \pm 8.6(32-63)$ & 25 \\
\hline Ye et al. [12] & 51 & $50(34-74)$ & 43 \\
\hline Feng et al. [22] & 48 & $56.8 \pm 11.2(27-75)$ & 52 \\
\hline Dong et al. [23] & 10 & $54 \pm 11.9(32-74)$ & 40 \\
\hline Wu et al. [24] & 50 & $44.3(-)$ & 56 \\
\hline Yang et al. [25] & 41 & $53.9 \pm 14.1(-)$ & 32 \\
\hline Lu et al. [26] & 62 & $56.4(37-79)$ & 58 \\
\hline Shi et al. [27] & 68 & $61(38-73)$ & 60 \\
\hline Hu et al. [28] & 13 & $62(38-70)$ & 23 \\
\hline Sun et al. [29] & 69 & $56.6 \pm 8.6(38-77)$ & 36 \\
\hline Abe et al. [30] & 14 & - & - \\
\hline Wu et al. [31] & 25 & $59 \pm 9(-)$ & 44 \\
\hline Zhang et al. [32] & 61 & - & - \\
\hline Li et al. [33] & 192 & $58.9 \pm 9.8(27-85)$ & 35 \\
\hline
\end{tabular}

\section{Results}

\section{Study selection}

A total of 343 records were identified by the Medline and Embase search. 67 duplicates were excluded, 226 non-pertinent records were excluded and 50 full-text articles were considered for inclusion. Of these potential papers, 35 were excluded ( $\triangleright$ Table 1). Finally, 15 original articles were included in final analysis [10-12, 22-33]. A flow diagram summarizing the procedure of study selection is presented in $\mathbf{P}$ Fig. $\mathbf{1}$.

\section{Study characteristics}

All of the included articles were performed in Asian countries (14 in China, 1 in Japan). With the exception of one multicenter study, all of the remnant were single-center studies. All but one prospective study were retrospective. The enrollment period ranged widely, from 2007 to 2017. The characteristics of the studies included in final analysis are summarized in $\mathbf{D}$ Table 2.

\section{Clinical characteristics}

A total of 750 patients were enrolled in the selected studies. The number of patients enrolled in each study ranged from 10 to 192 , with a median of 48 . The weighted average of the means age across the included studies was 55.9 years (range 44.3-66.5 years). The median of the male sex rate was $43 \%$ (range $23 \%-60 \%$ ) (> Table 3 ).

Overall, 750 gastric lesions were Eo-EFTR-treated in the included studies. The weighted average of the means tumor size was $2.04 \mathrm{~cm}$ (range $1.30-3.40 \mathrm{~cm}$ ). The clinical indication for
Eo-EFTR was MP-originating G-SMT, MP-originating gastric GIST and G-SMT with non-specified layer of origin in 10, 3 and 2 studies, respectively. The weighted average of the mean operation times was 67.5 minutes (range 31-128.7 minutes). As for the histopathological diagnosis of the Eo-EFTR resected gastric lesions, 488 were GISTs, 113 were leiomyomas, 8 were schwannomas and 16 were other types of tumors.

Histological diagnosis was not available in 50 of $750 \mathrm{G}$-SMTs [24]. Across two studies reporting 75 of 750 G-SMTs, data concerning final histopathological diagnosis could not be extrapolated from data coming from other resection techniques [30, 32]. Clinicopathological and technical characteristics of the included studies are summarized in $>$ Table 4.

\section{Outcomes}

Results and information on post-Eo-EFTR follow-up of the included studies are reported in $>$ Table 5 and $>$ Table 6, respectively.

\section{Primary outcomes}

Forteen studies including 750 gastric lesions provided information on the complete resection rate rate (i.e. en bloc resection with negative vertical and lateral resection margins at histology). The per-lesion rate of complete resection was $98.8 \%$. In addition, 15 studies including 750 lesions provided information on the surgical conversion rate (i.e. due to either Eo-EFTR failure or AEs). The per-lesion rate of surgical conversion was $0.8 \%$. Conversion to surgery was reported in three studies $[12,30$, 32], who described one, three, and two cases of surgical conversions, respectively. Among the six cases of surgical conversion reported across the included studies, laparoscopic surgery was performed in all cases. Conversion to laparoscopy was performed because of difficulty in endoscopic closure of the wall defect in three cases [30], whereas intraprocedural tumor fall into the peritoneal cavity [12], large size and hardness of the tumor [32] and difficulty of tumor dissection [32] were the cause of laparascopic conversion in the remnant three cases, respectively.

\section{Secondary outcomes}

Fifteen studies provided information on Eo-EFTR-related major AEs (i.e. delayed bleeding, delayed perforation, peritonitis, abdominal abscess and/or abdominal infection). The per-lesion reate of overall major AEs was $1.6 \%$. The per-lesion rate of delayed bleeding was $0.5 \%$. In all cases, delayed bleeding was resolved with endoscopic and conservative treatments, without requiring surgical intervention $[27,29,32]$.

The per-lesion rate of delayed perforation was $0.1 \%$.

Only the study from Sun et al. [29] reported one case of delayed perforation out of 69 Eo-EFTRs performed (1.45\%). The size of the Eo-EFTR treated G-SMT was $6 \mathrm{~cm}$ and the large wall defect was not easily closed, requiring an operative time of around 600 minutes. A percutaneous endoscopic gastrostomy was performed and the wall defect was efficiently closed with additional clips after the edema disappeared. Notably, in this study post-Eo-EFTR defect closure was performed by the use of standard clips only. 


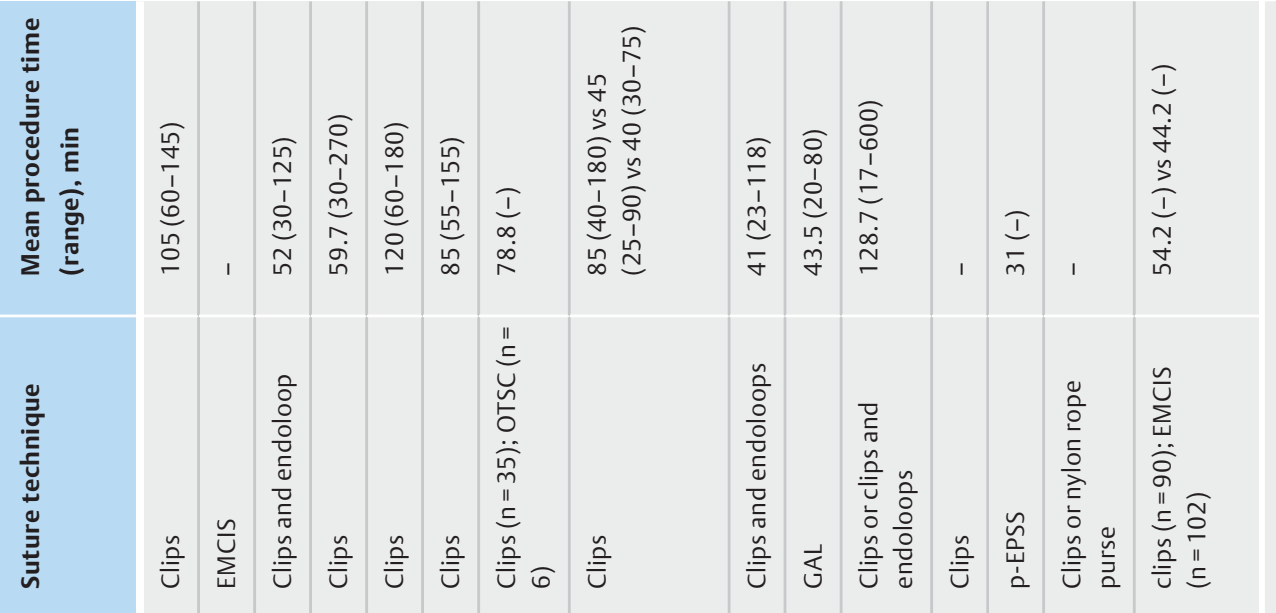

\begin{tabular}{|c|c|c|c|c|c|c|c|c|c|c|c|c|c|c|c|}
\hline 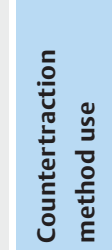 & 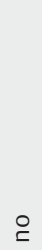 & $\stackrel{\circ}{\check{1}}$ & 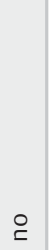 & 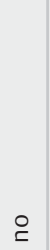 & $\stackrel{\circ}{\complement}$ & 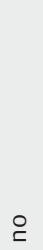 & 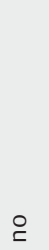 & 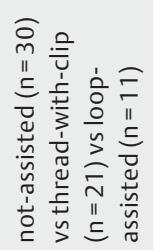 & 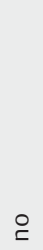 & $\stackrel{\circ}{\complement}$ & $\stackrel{\circ}{\check{2}}$ & 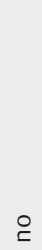 & $\stackrel{\circ}{\check{1}}$ & $\stackrel{\circ}{\complement}$ & 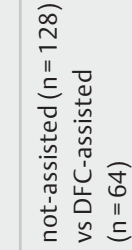 \\
\hline
\end{tabular}

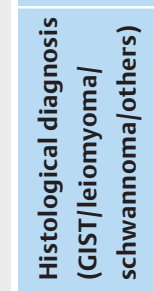

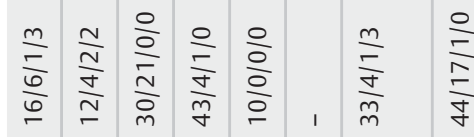

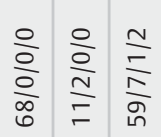

$\frac{\sqrt[n]{\frac{N}{n}}}{\frac{9}{2}}$

$\bar{\Sigma} \bar{\Sigma} \bar{\Sigma} \bar{\Sigma} \bar{\Sigma} \bar{\Sigma} \bar{\Sigma}$

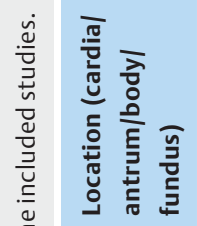

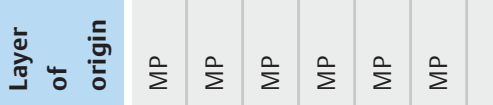

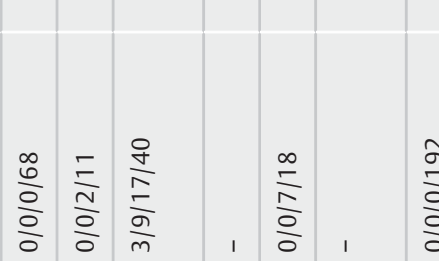

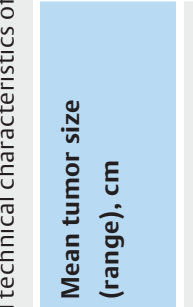

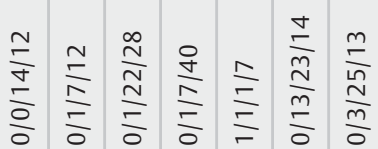

$\frac{m}{\frac{m}{a}} \frac{\stackrel{2}{\frac{0}{0}}}{\frac{0}{0}}$

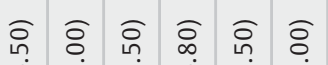

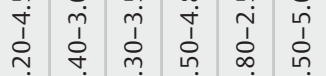

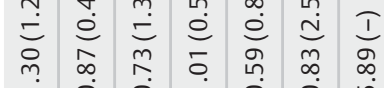

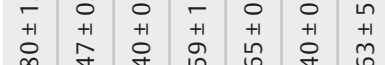

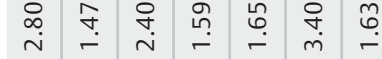

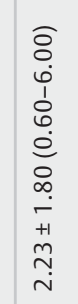

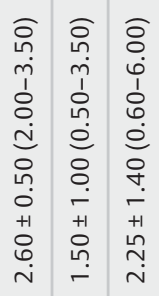

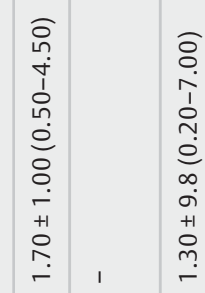

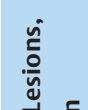

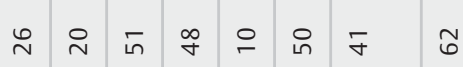

$\stackrel{\infty}{\sim}$ ঞ

$\pm \stackrel{\sim}{\sim} \check{\Omega}$

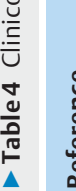

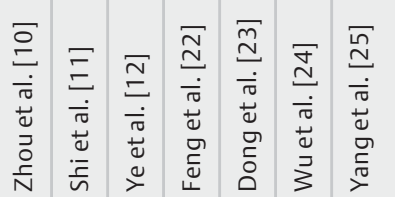

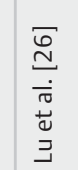

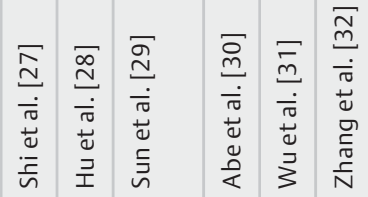

$\stackrel{m}{m}$

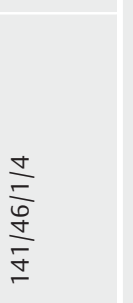


- Table 5 Success and major adverse event rate of exposed endoscopic full-thickness resection (Eo-EFTR).

\begin{tabular}{|c|c|c|c|c|c|c|c|c|}
\hline Reference & Lesions, n & $\begin{array}{l}\text { Complete } \\
\text { resection }\end{array}$ & $\begin{array}{l}\text { Surgical } \\
\text { conversion }\end{array}$ & $\begin{array}{l}\text { Successfull } \\
\text { Eo-EFTR }\end{array}$ & $\begin{array}{l}\text { Major } \\
\text { AEs }\end{array}$ & $\begin{array}{l}\text { Peritonitis, ab- } \\
\text { dominal abscess } \\
\text { or infection }\end{array}$ & $\begin{array}{l}\text { Delayed } \\
\text { perfora- } \\
\text { tion }\end{array}$ & $\begin{array}{l}\text { Delayed } \\
\text { bleeding }\end{array}$ \\
\hline Zhou et al. [10] & 26 & 26 & 0 & 26 & 0 & 0 & 0 & 0 \\
\hline Shi et al. [11] & 20 & 20 & 0 & 20 & 0 & 0 & 0 & 0 \\
\hline Ye et al. [12] & 51 & 50 & 1 & 50 & 0 & 0 & 0 & 0 \\
\hline Feng et al. [22] & 48 & 48 & 0 & 48 & 0 & 0 & 0 & 0 \\
\hline Dong et al. [23] & 10 & 10 & 0 & 10 & 1 & 1 & 0 & 0 \\
\hline Wu et al. [24] & 50 & 50 & 0 & 50 & 0 & 0 & 0 & 0 \\
\hline Yang et al. [25] & 41 & 41 & 0 & 41 & 0 & 0 & 0 & 0 \\
\hline Lu et al. [26] & 62 & 61 & 0 & 61 & 0 & 0 & 0 & 0 \\
\hline Shi et al. [27] & 68 & 68 & 0 & 68 & 1 & 0 & 0 & 1 \\
\hline Hu et al. [28] & 13 & 13 & 0 & 13 & 0 & 0 & 0 & 0 \\
\hline Sun et al. [29] & 69 & 69 & 0 & 68 & 4 & 2 & 1 & 1 \\
\hline Abe et al. [30] & 14 & 14 & 3 & 11 & 0 & 0 & 0 & 0 \\
\hline Wu et al. [31] & 25 & 25 & 0 & 25 & 0 & 0 & 0 & 0 \\
\hline Zhang et al. [32] & 61 & 59 & 2 & 59 & 6 & 4 & 0 & 2 \\
\hline Li et al [33] & 192 & 187 & 0 & 187 & 0 & 0 & 0 & 0 \\
\hline
\end{tabular}

- Table 6 Follow-up data after exposed endoscopic full-thickness resection (Eo-EFTR) and post-Eo-EFTR recurrence.

\begin{tabular}{|c|c|c|c|}
\hline Reference & Complete resection, $\mathbf{n}$ & Mean follow-up (range), months & Recurrence, $\mathbf{n}$ \\
\hline Zhou et al. [10] & 26 & $8(6-24)$ & 0 \\
\hline Shi et al. [11] & 20 & $6,8(2-13)$ & 0 \\
\hline Ye et al. [12] & 50 & $22.4(1-48)$ & 0 \\
\hline Feng et al. [22] & 48 & $-(2-24)$ & 0 \\
\hline Dong et al. [23] & 10 & $12.3(4-20)$ & 0 \\
\hline Wu et al. [24] & 50 & $1(1-1)$ & 0 \\
\hline Yang et al. [25] & 41 & - & - \\
\hline Lu et al. [26] & 61 & $7,6(2-24)$ & 0 \\
\hline Shi et al. [27] & 68 & $7(3-13)$ & 0 \\
\hline Hu et al. [28] & 13 & $5(1-15)$ & 0 \\
\hline Sun et al. [29] & 69 & $26(7-84)$ & 0 \\
\hline Abe et al. [30] & 14 & - & 0 \\
\hline Wu et al. [31] & 25 & $7(1-11)$ & 0 \\
\hline Zhang et al. [32] & 59 & - & 0 \\
\hline Li et al. [33] & 187 & $35(20-50)$ & 0 \\
\hline
\end{tabular}


$\checkmark$ Table 7 Risk of bias in the included individual studies, according to the Newcastle-Ottawa Scale.

\begin{tabular}{|c|c|c|c|c|c|c|c|c|c|}
\hline \multirow[t]{2}{*}{ Reference } & \multicolumn{4}{|c|}{ A. Selection } & \multirow{2}{*}{$\begin{array}{l}\text { B. Comparability } \\
\text { Comparability } \\
\text { of cohorts on the } \\
\text { basis of the de- } \\
\text { sign or aN/Alysis }\end{array}$} & \multicolumn{3}{|c|}{ C. Outcome } & \multirow{2}{*}{$\begin{array}{l}\text { Total } \\
\text { score }\end{array}$} \\
\hline & $\begin{array}{l}\text { Repre- } \\
\text { senta- } \\
\text { tiveness } \\
\text { of the } \\
\text { exposed } \\
\text { cohort }\end{array}$ & $\begin{array}{l}\text { Selec- } \\
\text { tion of } \\
\text { the } \\
\text { non ex- } \\
\text { posed } \\
\text { cohort }\end{array}$ & $\begin{array}{l}\text { Ascertain- } \\
\text { ment of } \\
\text { exposure }\end{array}$ & $\begin{array}{l}\text { Demon- } \\
\text { stration } \\
\text { outcome } \\
\text { of interest } \\
\text { non pres- } \\
\text { ent at start }\end{array}$ & & $\begin{array}{l}\text { Assess- } \\
\text { ment } \\
\text { of out- } \\
\text { come }\end{array}$ & $\begin{array}{l}\text { Ade- } \\
\text { quacy } \\
\text { of fol- } \\
\text { low } \\
\text { up co- } \\
\text { horts }\end{array}$ & $\begin{array}{l}\text { Was fol- } \\
\text { low-up } \\
\text { long e- } \\
\text { nough for } \\
\text { outcomes } \\
\text { to occur }\end{array}$ & \\
\hline Zhou et al. [10] & A & $\mathrm{N} / \mathrm{A}$ & A & A & $\mathrm{N} / \mathrm{A}$ & A & $A$ & $A$ & 6 \\
\hline Shi et al. [11] & A & $\mathrm{N} / \mathrm{A}$ & A & A & $\mathrm{N} / \mathrm{A}$ & A & A & A & 6 \\
\hline Ye et al. [12] & A & $\mathrm{N} / \mathrm{A}$ & A & A & $\mathrm{N} / \mathrm{A}$ & A & A & A & 6 \\
\hline Feng et al. [21] & A & $\mathrm{N} / \mathrm{A}$ & A & A & $\mathrm{N} / \mathrm{A}$ & A & A & A & 6 \\
\hline Dong et al. [22] & A & $\mathrm{N} / \mathrm{A}$ & A & A & $\mathrm{N} / \mathrm{A}$ & A & A & A & 6 \\
\hline Wu et al. [23] & A & $\mathrm{N} / \mathrm{A}$ & A & A & $\mathrm{N} / \mathrm{A}$ & $A$ & $A$ & $A$ & 6 \\
\hline Yang et al. [24] & A & $N / A$ & A & A & $\mathrm{N} / \mathrm{A}$ & $A$ & B & B & 4 \\
\hline Lu et al. [25] & A & $N / A$ & A & A & $\mathrm{N} / \mathrm{A}$ & $A$ & $A$ & $A$ & 6 \\
\hline Shi et al. [26] & A & $N / A$ & A & A & $\mathrm{N} / \mathrm{A}$ & $A$ & $A$ & $A$ & 6 \\
\hline Hu et al. [27] & A & $N / A$ & A & A & $\mathrm{N} / \mathrm{A}$ & A & A & A & 6 \\
\hline Sun et al. [28] & A & $N / A$ & A & A & $\mathrm{N} / \mathrm{A}$ & $A$ & $A$ & A & 6 \\
\hline Abe et al. [29] & A & $\mathrm{N} / \mathrm{A}$ & A & A & $\mathrm{N} / \mathrm{A}$ & A & B & B & 4 \\
\hline Wu et al. [30] & A & $\mathrm{N} / \mathrm{A}$ & A & A & $\mathrm{N} / \mathrm{A}$ & A & A & A & 6 \\
\hline $\begin{array}{l}\text { Zhang et al. } \\
\text { [31] }\end{array}$ & A & $N / A$ & A & $A$ & $\mathrm{~N} / \mathrm{A}$ & $A$ & B & B & 4 \\
\hline Li et al. [32] & A & $\mathrm{N} / \mathrm{A}$ & A & A & N/A & A & A & A & 6 \\
\hline $\begin{array}{l}\text { A. Selection } \\
\text { 1. Representativen } \\
\text { sion/exclusion crite } \\
\text { 2. Selection of the } \\
\text { 3. Ascertainment o } \\
\text { 4. Demonstration } \\
\text { B. Comparability } \\
\text { 1. Comparability of } \\
\text { C. Outcome } \\
\text { 1. Assessment of o } \\
\text { 2. Adequacy of foll } \\
\text { 3. Was follow-up lo } \\
\text { those lost suggesti } \\
\text { those followed or } ~ \\
\text { Score: } \mathbf{A}=\mathbf{1} ; \mathbf{B}=\mathbf{0} \text {. }\end{array}$ & $\begin{array}{l}\text { is of the expc } \\
\text { ia. } \\
\text { on exposed c } \\
\text { exposure-A: } \\
\text { tcome of int } \\
\text { ohorts on th } \\
\text { come-A: ind } \\
W \text {-up cohorts } \\
\text { g enough for } \\
g \text { no differen } \\
\text { statement. }\end{array}$ & $\begin{array}{l}\text { d cohort-A } \\
\text { ort-N/A: nc } \\
\text { amination } \\
\text { est non pres } \\
\text { asis of the } \\
\text { endent phy } \\
\text { : yes ( } \geq 1 \mathrm{~m} \\
\text { ttcomes to } \\
\text { from those }\end{array}$ & $\begin{array}{l}\text { ection from ge } \\
\text { plicable. } \\
\text { ocol or departn } \\
\text { at start-A: yes } \\
\text { gn or analysis- } \\
\text { an's assessmen } \\
\text { h); B: no (<1 n } \\
\text { Jr-A: complete } \\
\text { owed; B: follow }\end{array}$ & $\begin{array}{l}\text { Al population or } \\
\text { t's archive; B: n } \\
\text { no. } \\
\text { : not applicable } \\
\text { cord linkage; B: } \\
\text { h). } \\
\text { ow up or B: mir } \\
\text { rate< }<8 \% \text { and }\end{array}$ & $\begin{array}{l}\text { al loss to follow up ( } \leq \\
\text { description of losses to }\end{array}$ & $\begin{array}{l}\%) \text { all ages i } \\
\text { llow up or } ~\end{array}$ & $\begin{array}{l}\text { uded, all } \\
\text { cription s }\end{array}$ & $\begin{array}{l}\text { eases, or descri } \\
\text { jesting differer }\end{array}$ & $\begin{array}{l}\text { tion of } \\
\text { es from }\end{array}$ \\
\hline
\end{tabular}

The per-lesion rate of peritonitis, abdominal abscess and/or abdominal infection was $0.9 \%$.

Three studies reported the occurrence of peritonitis, abdominal abscess and/or abdominal infection. Dong et al. [23] reported one case of peritonitis out of 10 Eo-EFTR performed $(10 \%)$. Sun et al. [29] reported the occurrence of peritonitis in two patients (2/69; $2.9 \%)$, whereas another study reported four cases of abdominal infection $(4 / 61 ; 6.6 \%)$ [32]. In all cases, conservative treatment was effective with no need of surgical intervention. Of note, within the three studies reporting the post-operative occurrence of peritonitis, abdominal abscess and/or abdominal infection post-Eo-EFTR defect closure was performed by the use of standard clips only [23], standard clips or clips combined with endoloop in case of defect size larger then the width of the open clip [29] and standard clips or nylon rope purse [32].

Furthermore, Zhang et al. did not report routine use of perioperative antibiotics and intra-procedural capnoperitoneum management by use of percutaneously inserted angiocatheter [32].

Finally, the per-lesion rate of successful Eo-EFTR (i.e. complete resection of the tumor and effective endoscopic defect closure with neither delayed perforation occurrence nor surgical conversion need) was $98.3 \%$. 
No cases of recurrent tumors or mortality related to the EoEFTR procedure were observed in any of the included studies.

\section{Risk of bias in individual studies}

All selected studies were critically appraised for potential bias in relation to the outcomes of interest. No major selection bias was identified. The risk of bias was considered small in 12 studies with a quality score $=6$ and moderate in 3 studies having a quality score $=4$ ( $>$ Table 7 ).

\section{Discussion}

According to the NCCN guidelines, all suspected or histologically defined GISTs $>2 \mathrm{~cm}$ and GISTs $<2 \mathrm{~cm}$ that show high-risk EUS features shoud be surgically resected, due to their malignant potential [1]. Indeed, asymptomatic benign G-SMTs such as leiomyoma or lipomas may complicate (i. e. obstruction, bleeding or twisting) during tumoral growth. Finally, patients affected by suspected or defined GISTs $<2 \mathrm{~cm}$ often refuse long-term endoscopic follow-up, strongly requiring definitive treatment and diagnosis. In this setting, laparoscopic resection is currently regarded as the gold standard [1]. However, in the last decade, the minimally invasive and scarless Eo-EFTR technique without laparoscopic assistance has emerged as a new therapeutic modality with promising efficacy and safety in the resection of MP-originating G-SMTs [2-6]. Worldwide application of Eo-EFTR to MP-originating G-SMTs has been partially limited by the technical difficulty involved and safety concerns, especially regarding effective defect closure achievement and potential peritoneal infection. In our opinion, the recent availability of endoscopic suturing devices could help in overhelming these concerns.

In the present systematic review, 750 G-SMTs of which 647 arising from the MP were treated by Eo-EFTR without laparoscopic assistance. Our systematic review showed that this NOTES technique is an effective procedure for removing deep G-SMTs, with an R0 resection being achieved in $98.8 \%$ of the tumors. Despite the retrospective nature of all but one of the included studies, the strength and independence of the adopted reference standard (i.e. resection with negative margins at histological examination) may be expected to minimize the potential risk of recall bias. Indeed, no cases of tumor recurrence were reported in all but one included study providing followup.

Conversion to surgery due to either Eo-EFTR failure or AEs was needed in only $0.8 \%$ of the procedures. Our analysis also showed an excellent safety profile for gastric Eo-EFTR without laparoscopic assistance. Overall major AEs (i.e. delayed bleeding, delayed perforation, peritonitis, abdominal abscess and/or abdominal infection) occurred in only $1.6 \%$ of the cases, with peritonitis, abdominal abscess and/or abdominal infection being the most common major AEs ( $0.9 \%$ of the procedures). Delayed bleeding and delayed perforation have been shown by our study to occur extremely rarely, in only $0.5 \%$ and $0.1 \%$ of the procedures, respectively. In our opinion, these findings could confirm the safety of the Eo-EFTR approach, especially with regard to potential infection of the sterile peritoneal cavity after gastric active perforation creation.

Finally, according to our analysis, a successful Eo-EFTR procedure, defined by complete resection of the tumor and effective defect closure with neither delayed perforation occurrence nor surgical conversion need, was achieved in $98.3 \%$ of the cases.

This study has some notable limitations. First, with regard to study design, all but one of the included studies were retrospective, but they also embraced very long enrollment periods, thus variable learning-curve and post-training experience were likely to occur across the included studies. The follow-up period of recurrence also was not long enough and differed significantly. However, it did not affect the primary and secondary outcomes. Regarding Eo-EFTR feasibility, standardization of the procedure is poor and a wide variety of different cutting devices, accessories, countertraction and endoscopic closure techniques have been used. All of the included studies were from Asian countries with no western country contributions. Because of high heterogeneity among the selected studies, we did not conduct meta-analysis and performed qualitative integration in this systematic review

\section{Conclusion}

In conclusion, this is the first systematic review providing information on the efficacy and safety profile of Eo-EFTR without laparoscopic assistance for removal of deep G-SMTs. Considering the high complete resection and overall successfull Eo-EFTR rates and the low major AE rates, Eo-EFTR without laparoscopic assistance appears to be an effective and safe minimally invasive treatment modality, at least in expert hands, for patients with deep G-SMTs. Better Eo-EFTR procedure standardization and a more widespread adoption in Western countries are required. Large prospective studies evaluating gastric Eo-EFTR are strongly desired.

\section{Competing interests}

The authors declare that they have no conflict of interest.

\section{References}

[1] von Mehren M, Randall RL, Benjamin RS et al. Soft Tissue Sarcoma, Version 2. 2018, NCCN Clinical Practice Guidelines in Oncology. J Natl Compr Canc Netw 2018; 16: 536-563

[2] Cai M, Zhou P, Lourenço LC et al. Endoscopic full-thickness resection (EFTR) for gastrointestinal subepithelial tumors. Gastrointest Endosc Clin N Am 2016; 26: 283-295

[3] Jain D, Mahmood E, Desai A et al. Endoscopic full thickness resection for gastric tumors originating from muscularis propria. World J Gastrointest Endosc 2016; 8: 489-495

[4] Cai MY, Martin Carreras-Presas F, Zhou PH. Endoscopic full-thickness resection for gastrointestinal submucosal tumors. Dig Endosc 2018; 30: $17-24$ 
[5] Mori H, Kobara H, Nishiyama N et al. Current status and future perspectives of endoscopic full-thickness resection. Dig Endosc 2018; 30: $25-31$

[6] Zhang X, Modayil R, Criscitelli T et al. Endoscopic resection for subepithelial lesions-pure endoscopic full-thickness resection and submucosal tunneling endoscopic resection. Transl Gastroenterol Hepatol 2019; 4: 39

[7] Suzuki H, Okuwaki S, Ikeda K et al. Endoscopic full-thickness resection (EFTR) and waterproof defect closure (ENDC) for improvement of curability and safety in endoscopic treatment of early gastrointestinal malignancies (in Japanese, English abstract). Prog Dig Endosc 1998; 52: 49-53

[8] Suzuki H, Ikeda K. Endoscopic mucosal resection and full thickness resection with complete defect closure for early gastrointestinal malignancies. Endoscopy 2001; 33: 437-439

[9] Ikeda K, Mosse CA, Park PO et al. Endoscopic full-thickness resection: circumferential cutting method. Gastrointest Endosc 2006; 64: 8289

[10] Zhou PH, Yao LQ, Qin XY et al. Endoscopic full-thickness resection without laparoscopic assistance for gastric submucosal tumors originated from the muscularis propria. Surg Endosc 2011; 25: 2926-2931

[11] Shi Q, Chen T, Zhong YS et al. Complete closure of large gastric defects after endoscopic fullthickness resection, using endoloop and metallic clip interrupted suture. Endoscopy 2013; 45: 329-334

[12] Ye LP, Yu Z, Mao XL et al. Endoscopic fullthickness resection with defect closure using clips and an endoloop for gastric subepithelial tumors arising from the muscularis propria. Surg Endosc 2014; 28 : 1978-1983

[13] Guo J, Liu Z, Sun S et al. Endoscopic full-thickness resection with defect closure using an over-the-scope clip for gastric subepithelial tumors originating from the muscularis propria. Surg Endosc 2015; 29 : 3356-3362

[14] Andalib I, Yeoun D, Reddy R et al. Endoscopic resection of gastric gastrointestinal stromal tumors originating from the muscularis propria layer in North America: methods and feasibility data. Surg Endosc 2018; 32: 1787-1792

[15] Azzolini F, Cecinato P, lori V et al. Endoscopic full-thickness resection for suspected residual rectal neuroendocrine tumor and closure of the defect with a new suturing system. Endoscopy 2015; 47: E556E557

[16] Xu MM, Angeles A, Kahaleh M. Endoscopic full-thickness resection of gastric stromal tumor: one and done. Endoscopy 2018; 50: E42-E43

[17] Granata A, Bisello M, Cipolletta F et al. Endoscopic wedge gastrectomy of a gastric subepithelial tumor and closure of the gastric wall defect with the overstitch suturing system. Surg Innov 2018; 25: 542-543

[18] Granata A, Amata M, Ligresti D et al. Underwater full-thickness resection of a duodenal bulb gastrointestinal stromal tumor with OverStitch defect repair. Endoscopy 2019; 51: E207-E208

[19] Dedania B, Mistry T, Buryanek J et al. Endoscopic full-thickness resection of a gastric subepithelial tumor. VideoGIE 2018; 3: 79-80

[20] Liberati A, Altman DG, Tetzlaff ] et al. The PRISMA statement for reporting systematic reviews and meta-analyses of studies that evaluate health care interventions: explanation and elaboration. Ann Intern Med 2009; 151: 65-94
[21] Wells GA, Shea B, O'Connell D et al. The Newcastle-Ottawa Scale (NOS) for assessing the quality of nonrandomised studies in metaanalyses. 2010: http://www.ohri.ca/programs/clinical_epidemiology/oxford.asp (Accessed 2020 Apr 6)

[22] Feng Y, Yu L, Yang $S$ et al. Endolumenal endoscopic full-thickness resection of muscularis propria-originating gastric submucosal tumors. I Laparoendosc Adv Surg Tech A 2014; 24: 171-176

[23] Dong HY, Wang YL, Jia XY et al. Modified laparoscopic intragastric surgery and endoscopic full-thickness resection for gastric stromal tumor originating from the muscularis propria. Surg Endosc 2014; 28: 1447-1453

[24] Wu CR, Huang LY, Guo ] et al. Clinical Control Study of Endoscopic Full-thickness Resection and Laparoscopic Surgery in the Treatment of Gastric Tumors Arising from the Muscularis Propria. Chin Med J (Engl) 2015; 128: 1455-1459

[25] Yang F, Wang S, Sun S et al. Factors associated with endoscopic fullthickness resection of gastric submucosal tumors. Surg Endosc 2015; 29: $3588-3593$

[26] Lu J, Jiao T, Li Y et al. Facilitating retroflexed endoscopic full-thickness resection through loop-mediated or rope-mediated countertraction (with videos). Gastrointest Endosc 2016; 83: 223-228

[27] Shi D, Li R, Chen W et al. Application of novel endoloops to close the defects resulted from endoscopic full-thickness resection with singlechannel gastroscope: a multicenter study. Surg Endosc 2017; 31 : 837-842

[28] Hu JW, Ge L, Zhou PH et al. A novel grasp-and-loop closure method for defect closure after endoscopic full-thickness resection (with video). Surg Endosc 2017; 31: 4275-4282

[29] Sun M, Song J, Song X et al. Endoscopic full-thickness resection for gastric subepithelial tumors originating from the muscularis propria: a 69-case series. Surg Laparosc Endosc Percutan Tech 2018; 28: e12e17

[30] Abe N, Takeuchi H, Ohki A et al. Comparison between endoscopic and laparoscopic removal of gastric submucosal tumor. Dig Endosc 2018; 30: (Suppl. 01): 7-16

[31] Wu N, Liu S, Chen M et al. The prepurse-string suture technique for gastric defect after endoscopic full-thickness resection (with video). Medicine (Baltimore) 2018; 97: e12118

[32] Zhang H, Huang X, Qu C et al. Comparison between laparoscopic and endoscopic resections for gastric submucosal tumors. Saudi J Gastroenterol 2019; 25: 245-250

[33] Li B, Shi Q, Qi ZP et al. The efficacy of dental floss and a hemoclip as a traction method for the endoscopic full-thickness resection of submucosal tumors in the gastric fundus. Surg Endosc 2019; 33: 38643873

\section{CORRECTION}

Antonino Granata, Alberto Martino, Michele Amata et al. Efficacy and safety of gastric exposed endoscopic full-thickness resection without laparoscopic assistance: a systematic review

Endoscopy International Open 2020; 08: E1173-E1182.

DOI: $10.1055 / a-1198-4357$

In the above mentioned article the order of given name and surname was switched. Correct is:

Antonino Granata, Alberto Martino, Michele Amata, Dario Ligresti, Fabio Tuzzolino, Mario Traina 